\title{
Countermeasures for Psychological Health Education of Post-95s College Students in the New Period
}

\author{
Shucheng Wei ${ }^{1, a^{*}}$ and Juan Yin ${ }^{2, b}$ \\ ${ }^{1}$ Zaozhuang University, Zaozhuang, Shandong, China \\ ${ }^{2}$ Binhe Road, Zaozhuang, Shandong, China \\ aweishucheng2008@163.com, bhoneyjuan2008@163.com
}

Keywords: College students' mental health education course; Team cooperation; Interpersonal relationship; Emotion management; Teaching evaluation

\begin{abstract}
In order to implement college students' mental health education curriculum of the Ministry of Education and improve the teaching quality of mental health education curriculum, experts of Southwest Jiaotong University changed the traditional "spoon feeding" teaching method. They pay attention to the use of real life examples about students' concern, let the students participate in experiential learning, teaching content and strengthen the construction of teachers and teaching materials, strengthen the establishment of performance evaluation mechanism of multiple incentives. They emphasize that building up the students' mental health education curriculum system is so important that they could learn how to manage emotions. Great progress has been made, and it has played a positive guiding role in the healthy growth of the people.

In recent years, students have been criticized for the examination of teachers and parents or other reasons. According to statistics, the number of college students having mental health problems dropped about $30 \%$. About $20.3 \%$ people have obvious psychological obstacles. What causes the lack of students' Outlook on life? Why don't they know how to treasure their lives? These are facts that can not be ignored.
\end{abstract}

\section{Psychological Health Education of Post-95s College Students}

The meaning of psychological health refers to the normal development of the intelligent base formed by knowledge, emotion and personality characteristics showed good interpersonal skills and interpersonal relationship is the internal form of health. Mental health education's connotation is based on the physiological and psychological development characteristics. Counseling education and good behavior training is a kind of emotional experience and spiritual communication. The concept of identity promotes the all-round development of education activities. It has a unique effect on the students' ability to adapt to society [1].

\section{The Necessity of Mental Health Education Innovation of Post-95s College Students}

The Implementation of Psychological Education in Colleges and Universities is the Inevitable Requirement of Higher Education. The harmonious development of the three aspects of knowledge, ability and personality is the concept of all-round development advocated by contemporary society, and also the educational concept of contemporary higher education. According to this idea, to help college students build a life building with material support, spiritual support and social support as an important pillar, will become the historical mission of Contemporary colleges and universities. Strengthening the psychological health education of college students and improving their psychological quality not only meet the development of the times, but also show the characteristics of modern education. Therefore, the implementation of college students' mental health education is not only an important content of ideological and political education for college students, but also a major measure for college students to implement quality education. Thought exists as the forerunner of action and all activities of college students are based on psychological activities. If college students do not have good psychological quality and 
can not accept mental health education, it will affect the mastery of scientific and cultural knowledge. The ideological problems of college students often reflect the psychological factors, such as lack of learning motivation, interpersonal conflict, a slight setback, immediate retreat, emotional easily out of control and so on. It is usually directly related to psychological factors, such as endurance, control, coordination and so on. For this kind of psychological problems, it is best to use psychological methods to deal with. Therefore, the psychological health education of college students is the basic project of talent training in colleges and universities and is indispensable to quality education in colleges and universities.

The Implementation of Psychological Education in Colleges and Universities is the Realistic Demand of Harmonious Development. In the process of individual socialization, the harmonious development of college students' psychology is the core part of their overall quality. Only when students have mental health, can they correctly understand the reality. They have good interpersonal relationship, face setbacks with positive attitude and have the courage to overcome difficulties. Mental health of college students is the foundation of good moral character, which is related to the efficiency of intelligence activities, and contributes to the development of physical health and aesthetic education. It is one of the main tasks of mental health education in colleges and universities to form a harmonious personality through mental health education. Contemporary college students have unique imprint of the times. Advocating scientific spirit, pursuing independent will, bringing forth new ideas and individuality are the advantages of college students. At the same time, it is easy to be extreme and rebellious, and it is also a problem that college students must face. The psychological health education of college students is to help the harmonious development of them. College students should have the tolerance of others, learn to accept others, understand others, and get along well with each other. College students should have the ability to adapt to society, take the initiative to focus on the community and adapt to society. College students should live in harmony with nature, follow the laws of nature and make use of nature scientifically and rationally, so as to achieve harmony between man and nature. College students should be aware of themselves. Only by fully understanding themselves can they correctly understand themselves, evaluate themselves and accept themselves. Colleges and universities should pay attention to students' mental health education so as to make every college students accept mental health education and training, so as to cultivate healthy psychological personality and better psychological ability and promote the harmonious development of talents.

The Implementation of Psychological Education in Colleges and Universities is the Necessary Way to Develop Potential. Human potential development is mainly based on two aspects of accumulation: on the one hand is the genetic quality of human life evolution over hundreds of millions of years; on the other hand, it is the spiritual wealth of human social practice for millions of years. Genetic quality is innate, born and possessed and spiritual wealth is acquired by learning. Education enables the descendants to stand on the shoulders of their predecessors, stand higher, look farther, and thus promote the development of human society. College students' mental health education has its own professional knowledge and scientific methods, which can not be simplified and localized in the ordinary teaching. According to the view of contemporary intelligence, human intelligence is made up of a variety of intellectual factors. The reason why each person's intelligence is different is caused by the different combination of various intelligence factors. What matters between man and woman is not who is cleverer than who is, but how clever and wise every man is. The potential of college students needs to be further developed. The key point is that mental health education in colleges and universities should provide the necessary guidance, so that students can understand their own intellectual structure and master the corresponding means of development.

\section{Specific Factors Affecting Post-95s College Students' Mental Health}

Factors of Society. The current society has bad social customs, unhealthy ideology. The gap between rich and poor is one of the factors that threaten students' psychological health threat. The individual values of the students is inclined, especially affect some pornographic things on the 
mental health of college students, so that they can easily go astray.

Factors of School. Colleges and universities are the main place for the formation of college Students' Outlook on life, values and morality. Most of the schools have factors that induce psychological barriers. First of all, the psychological confusion and obstacles caused by the disharmony of interpersonal communication among individual students, the lack of courage and method of communication with others is existing. Furthermore, learning is the main content of college students, accompanied by the deepening of learning content, competition among students, social employment situation and family expectations of college students, resulting in increased tension and pressure of college students. What's more, students are defenseless against bad code or easy to accept and contrary to mainstream social norms and values of the concept. The last is that the students mistakenly believe that the body "disease is healthy", "no defect is health". Schools offer mental health courses to impart psychological health knowledge to students. Some of them accept passively and have a negative attitude towards mental health education. Under normal circumstances, it is difficult for schools to guarantee the systematicness and coverage of mental health education and the level of mental health is not increasing. The need for healthy psychological development can not be satisfied. It is necessary to demonstrate the urgency, necessity and difficulty of mental health education.

Family Factors. Family is the cradle of students' growth and it is the first class of students. The influence of family factors on children is lifelong and the behavior of parents exerts a subtle influence on children. Family education has extremely important significance for the growth of children and it is also deep-rooted. Many of the psychological problems of the students and family background are closely related to family relationships. Many parents only care about their children's academic achievements and daily life, the rest are not concerned. From the economic point of view, the poor college students psychologically prone to inferiority and they are not confident.

Internal Factors. At present, college students are a group of post-95s young people who are extremely sensitive groups and their inner experience is extremely delicate. With the expansion of cultural level and living space, many inner factors affected the mental health of college students. The contradiction between ideal and reality, and the contradiction between emotion and reason leads to fracture of some weak willed personality and psychology. A few students are affected by money worship and hedonism. Luxury and pleasure is the biggest target pursuit of life. Because the reality is not ideal and cynical, all thoughts are blasted. It leads to endless stay in tension, anxiety, worry, frustration and unbalanced state. I do not know how to keep up with ambition and unrealistic employment of greed, this kind of education as the free development view and universal view of little importance is one-sided and incorrect[2].

\section{The Effective Ways to Innovate the Mental Health Education Mode of Post-95s College Students}

Changing the Concept of Psychological Education in Colleges and Universities. The concept of college students' mental health education refers to the basic understanding and basic attitude of college educators to the psychological health education of college students. It is an ideal and stable paradigm for the development of college students' mental health education, which usually has the characteristics of guidance and foresight. What kind of mental health education concept the university educators hold directly determines their educational value orientation and pursuit, influences their choice of educational theory and exploration of educational practice, and restricts the effectiveness of their mental health education. Therefore, it is very important to change the concept of college students' mental health education. In the past, psychological health education focused on psychological counseling, but neglected health education, while psychological counseling was mostly obstacle counseling, while developmental counseling was rare. It is generally believed that only the students with psychological barriers need to become the object of psychological consultation, and the students who are puzzled by their studies and employment are not related to psychological counseling. It is true that therapeutic counseling is an essential part of college students' mental health education. However, it is also important to improve the mental 
health of college students and pay attention to the prevention and development of their mental health, and it is especially important in the long run. Therefore, the university mental health education should change the focus from treatment to prevention, expand the object of psychological health education of college students and fully reflect the comprehensiveness and effectiveness of college students' mental health education.

Perfecting the Psychological Education Team in Colleges and Universities. According to the system theory, the mental health education of college students should be included in the overall talent training system of colleges and universities. The construction of psychological education team in universities should be included in the construction of university teachers and the construction of teachers' morality. The Ministry of Education and the Ministry of Health jointly issued a document, pointed out that colleges should strengthen the construction of college students' mental health education team. According to system theory, absorbing the spirit of the relevant documents, combined with the actual construction of universities, college students, consisting of "four in one" college psychological education team, can achieve top-down contact and interaction and can realize mutual connection and interaction between the students of each other, so as to eliminate the shortcomings of the previous single mode of team building. The college psychological education in the construction of four in one "of the specific content, is the establishment of the leadership of the head, the leadership of the relevant departments for supervision work in the steering group members. They have to employ the relevant experts to provide psychological counseling and training。 The organizations set up by the department of counselors based specialist are responsible for the specific work of the implementation, from the selection of college students' psychological quality the" soul "play a role of peer support.

Innovating the Carrier of Psychological Education in Colleges and Universities. College Students' dormitory area constantly enrich and update the content, so that students have subtle influence, not only beneficial to the understanding of the connotation of college students' mental health, but also helps to discover the abnormal psychological health of college students, so as to timely treatment. Through the picture or the form of writing to introduce the experience of overcoming psychological barriers, encourage mental health problems of college students dare to face the reality, actively cooperate with the treatment, so as to enhance the psychological health of college Students' sense of responsibility. College Students' psychological counseling center, college counselors should actively adopt various ways of college Students' psychological health education propaganda, for example, in an interview conducted by the campus radio or newspaper is guided by the manual of mental health education; through the campus network open column comments, discussion and interaction. College students' mental health organizations or college students' psychological counseling centers can regularly carry out different mental health education activities on different topics.

Constructing the Psychological Education Environment in Colleges and Universities. Human behavior is usually the result of the combination of psychological factors and environmental factors. The psychological education environment has a great influence on college students' mental health. In the past, college students' mental health education was used to focus on the learning space of themselves, and less or never considered the living space of College students. The current mental health education in Colleges and universities should strive to create a comprehensive psychological education environment. In any field of college students' activities, college students' psychological health education should be involved, and strive to eliminate the blind spots of mental health education, so that college students can feel the love from the heart at any time and place, and get useful advice and assistance [3].

In a word, post-95s college students as builders and successors of socialism, is the precious talent resources of the party and the country. Along with the complexity of the social environment and the problems encountered in the process of the growth, college students must have the correct evaluation of their own. Consciously paying attention to mental health training, good psychological quality, increasing interest in learning, reinforcement learning motivation, make their own comprehensive quality all-round development and realize their value in life. 


\section{References}

[1] Q.Y. Huang: College Students' Mental Health Education Curriculum Reform (Educational Science Publishing House, China 2011).(In Chinese).

[2] C.Y. Liao: Journal of the Chinese Society of Education,(1995) No.4,p.29.(In Chinese).

[3] Q. Zheng, M. Guo and M. Liu: Journal of Southwest Jiaotong University (2012) No.5,p.120.(In Chinese). 